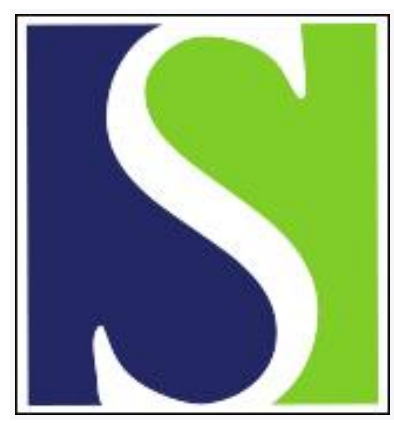

Scand J Work Environ Health 2017;43(3):217-225

https://doi.org/10.5271/sjweh.3615

Published online: 16 Dec 2016, Issue date: 01 May 2017

Transient risk factors of acute occupational injuries: a case-crossover study in two Danish emergency departments by Østerlund AH, Lander F, Nielsen K, Kines P, Möller J, Lauritsen J

In spite of numerous prevention efforts occupational injuries continue to be a global challenge. A case-crossover design was used to examine the effect of eight specific transient risk factors for acute occupational injuries. The study identified several transient risk factors that led to significantly increased risks for occupational injuries, particularly for equipment and work practice-related factors.

Affiliation: Accident Analysis Group (UAG), Department of Orthopedic Surgery, Odense University Hospital, Sdr. Boulevard 50, DK- 5000 Odense, Denmark. jens.lauritsen@rsyd.dk

Refers to the following text of the Journal: 2012;38(2):163-170

The following article refers to this text: 2017;43(3):191-195

Key terms: accident; acute occupational injury; acute work injury; case-crossover study; Denmark; emergency department; matched-pair interval approach; occupational injury; risk factor; transient risk factor; work injury

This article in PubMed: www.ncbi.nlm.nih.gov/pubmed/27984595

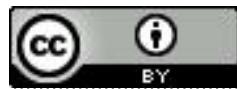




\title{
Transient risk factors of acute occupational injuries: a case-crossover study in two Danish emergency departments
}

\author{
by Anna $\mathrm{H}$ Østerlund, MSc, ${ }^{1,2}$ Flemming Lander, PhD, ${ }^{3}$ Kent Nielsen, PhD, ${ }^{4}$ Pete Kines, PhD, ${ }^{5}$ Jette \\ Möller, PhD, ${ }^{6}$ Jens Lauritsen, $P h D^{1,2}$
}

\begin{abstract}
Østerlund AH, Lander F, Nielsen K, Kines P, Möller J, Lauritsen J. Transient risk factors of acute occupational injuries: a case-crossover study in two Danish emergency departments. Scand J Work Environ Health. 2017;43(3):217-225. doi:10.5271/sjweh.3615
\end{abstract}

Objectives The objectives of this study were to (i) identify transient risk factors of occupational injuries and (ii) determine if the risk varies with age, injury severity, job task, and industry risk level.

Method A case-crossover design was used to examine the effect of seven specific transient risk factors (time pressure, disagreement with someone, feeling sick, being distracted by someone, non-routine task, altered surroundings, and broken machinery and materials) for occupational injuries. In the study, 1693 patients with occupational injuries were recruited from a total of 4002 occupational injuries seen in 2013 at two emergency departments in Denmark. Effect estimates were calculated using the matched-pair interval approach.

Results Increased risk for an occupational injury was found for time pressure [odds ratio (OR) 1.6, $95 \%$ confidence interval $(95 \% \mathrm{CI}) 1.3-2.0$ ], feeling sick (OR 2.7, 95\% CI 1.9-3.9), being distracted by someone (OR $3.1,95 \%$ CI 2.3-4.1), non-routine task (OR 8.2, 95\% CI 5.3-12.5), altered surroundings (OR 20.9, 95\% CI 12.2-35.8), and broken machinery or materials (OR 20.6, 95\% CI 13.5-31.7). The risk of occupational injury did not vary substantially in relation to sex, age, job task, industry risk level, or injury severity.

Conclusion Use of a case-crossover design identified several worker-related transient risk factors (time pressure, feeling sick, being distracted by someone) that led to significantly increased risks for occupational injuries. In particular, equipment (broken machinery or materials) and work-practice-related factors (non-routine task and altered surroundings) increased the risk of an occupational injury. Elaboration of results in relation to hazard period and information bias is warranted.

Key terms accident; acute work injury; Denmark; equipment factor; exposure suspicious bias; hazard bias; information period; matched-pair interval approach; trigger; work injury; work-practice-related factor.

The annual global burden of occupational injuries has been estimated to be approximately 100 million injuries with 100000 deaths (1). In Denmark, the number of occupational injuries is still high with approximately 40000 incidents treated each year in emergency departments (ED) in a working population of around 2.5 million $(2,3)$. Additionally, about 40000 injuries are reported to the Danish Working Environment Authority (DWEA), of which only around $16 \%$ have been treated in an ED (2). Occupational injury research has mainly focused on stable risk factors such as lack of job experience, lack of safety culture, night shifts, inadequate use of protective equipment and hazardous job types (eg, construction, mechanical fitter), which have been found to increase the risk of occupational injuries (3, 4). Although important for preventive strategies, these broad factors can be difficult to target.

Injury prevention is most successful if the etiology of an injury is understood so that efforts can be focused more directly (5). Identifying short-term risk factors that

\footnotetext{
1 Accident Analysis Group, Department of Orthopedic Surgery, Odense University Hospital, Odense, Denmark.

2 Institute of Clinical Research, University of Southern Denmark, Odense, Denmark.

3 Department of Occupational Medicine, Odense University Hospital, Odense, Denmark.

4 Department of Occupational Medicine, Regional Hospital West Jutland, Herning, Denmark.

5 National Research Centre for the Working Environment, Copenhagen, Denmark.

6 Department of Public Health Sciences, Karolinska Institutet, Stockholm, Sweden.
}

Correspondence to: Jens Lauritsen, Accident Analysis Group (UAG), Department of Orthopedic Surgery, Odense University Hospital, Sdr. Boulevard 50, DK- 5000 Odense, Denmark. [E-mail: jens.lauritsen@rsyd.dk] 
lead to occupational injuries, including person-related transient risk factors, could help to understand the mechanisms behind injuries and thus improve prevention efforts (6). Previous case-control and cohort studies have examined the effect of some of these transient exposures on occupational injuries, especially concerning machinery and surroundings. However, these studies have not looked at potentially important person-oriented transient risk factors such as perceived time pressure, feeling sick, and having a disagreement with or being distracted by someone, and few studies have studied aspects of work practice eg, non-routine task or altered surroundings (7-13).

A case-crossover design is well-suited to examine transient risk factors as the case is self-matched, ie, exposure in the interval immediately before an outcome (injury) occurs is compared to exposure during a previous time interval when the outcome did not occur (14). Accordingly, each individual serves as their own control, and confounders that remain constant over the compared periods (age, gender, specific job task, experience etc) are inherently adjusted for, in contrast to the standard case-control design $(15,16)$. Another advantage of case-crossover compared to case-control studies is that transient risk factors that occur in close sequence to exposure can be examined (17). The design has previously been used to study the influence of different transient risk factors on occupational injuries, for instance, malfunctioning equipment, unusual work methods, performing an unusual task, and being tired, ill, distracted or rushed (18-20).

Previous studies show great variation in odds ratios (OR) for the same transient risk factor depending on the analysis method used (eg, usual frequency or matched-pair interval approach). However, it is seen that although OR vary, the direction of the outcome is the same $(>$ or $<1)$. Furthermore, results from previous studies highlight that equipment-related factors seem to have the highest OR followed by practice-related factors and subsequently worker-related factors. However, only one study (14) has highlighted these tendencies in risk estimates.

Most previous studies have focused on specific injuries, eg, hand or eye injuries $(14,18,20,21)$ or specific industries, such as pork processing and commercial fishing $(18,22)$. However, there is a need to compare the influence of transient risk factors across different kinds of occupational injuries and injury severity (23).

The aim of the present case-crossover study was to determine the risk impact of transient risk factors on occupational injuries treated at emergency departments, and whether this risk differs according to age, sex, job task, industry risk level and injury severity.

\section{Methods}

\section{Study design}

A case-crossover design was employed using the matched-pair interval approach with the previous day at the same time as the injury as control period (16).

\section{Setting}

The population base for this study emerged from two Danish emergency departments (ED): Odense University Hospital (OUH) and Herning Hospital (HH) during 2013. All counts refer to persons seeking treatment at the ED due to an acute occupational injury. The study population is thus, referred to as "injured persons", regardless of the actual contact diagnosis.

\section{Procedure and participants}

A total of 4002 occupationally injured persons arrived at the ED (target population). Inclusion criteria consisted of: (i) contacting one of the two ED due to an occupational injury (defined as a sudden, unexpected event occurring during paid work) (24), (ii) age 18-70 years, and (iii) being able to speak and understand one or more of the Scandinavian languages. Upon presentation at the ED, potential participants were informed about the study and asked to take part (basic questionnaire) by one of the ED secretaries; a total of 2396 injured persons (59\%) agreed to participate. Within a few weeks, a member of the project team contacted the injured person by telephone (average 15 days, percentiles: $25 \%=3$ days and $75 \%=20$ days) and conducted an interview of approximately 20 minutes based on a structured questionnaire concerning demographic characteristics, exposure to any of the transient risk factors in the case- and controlperiod (described below), and health- and job-related factors. The basic questionnaire and interview data were merged using a unique 10-digit civil registration system (CRS) and date of injury, so one person could potentially be included several times [ 1 injury $(\mathrm{N}=1590), 2$ injuries $(\mathrm{N}=92), \geq 3$ injuries $(\mathrm{N}=11)]$ (25). Additional information on injury and industry profiles acquired from records at the two emergency departments were also merged by the CRS number. When all data were gathered, they were anonymized.

The analytic sample comprised those who had completed all exposure questions in the telephone interview. A total of 1693 (42\%) qualified for inclusion in the study. Response rates were comparable for the two participating hospitals: $43 \%$ at $\mathrm{OUH}$ and $42 \%$ at $\mathrm{HH}$. There was selective participation in the telephone interview in regard to age (dichotomized at 30 years), but not in relation to sex, injury severity, job task or industry risk 
level. This suggested that our relatively low response rate of $42 \%$ did not influence the validity of the study, with the exception of fewer younger injured persons in the respondent group compared to non-respondents (26).

\section{Transient risk factors}

On the basis of previous case-crossover studies and existing occupational injury theory, seven potential transient risk factors were measured: four worker-related (time pressure, disagreement with someone, feeling sick, and being distracted by someone), two work-practicerelated (non-routine task and altered surroundings), and one equipment-related (working with broken machinery or materials) $(18,20-23,27-29)$. For each factor, the injured person exposure at the time of the injury and during the previous work day. The question in Danish translated to English read: "Did you experience time pressure at the time of the injury?", with comparable formulations for the other transient risk factors. Both case- and control-period information was gathered simultaneously. Length of the hazard period was defined with the same time scope for all transient risk factors.

\section{Covariates}

Information on covariates was categorized as follows: sex, age, injury severity, job task, and job risk at industry level (table 1). Consistent with previous studies, fewer females had an occupational injury (2). Age was dichotomized ( $<30 / \geq 30$ years) in order to represent different work safety experience and also differences in risk taking. $(2,26)$. WHO-ICD10 injury diagnoses were categorized into "major" (fractures, loss of body part, major burns, loss of sight, electric shock, hypothermia, loss of consciousness, dislocation of shoulder/ knee/ hip/ spine, all types of soft tissue damage, and joint sprain and strains) and "minor" (superficial lacerations and wounds, a foreign body in the eye and unspecific observational diagnoses (Z-diagnoses) injuries $(2,24)$. Minor induries accounted for two-thirds of all the occupational injuries. Information on occupational industry settings were based on self-reported information on company address, company name, and job task. Individual job task was coded as "temporary" versus "stationary" as a standardization of the job function for each injured person. A stationary job task was defined as work performed mainly in the same physical place and with the same function (eg, line workers in manufacturing industries), whereas a temporary job task was characterized by frequent alterations between different, dynamic and new work sites (eg, construction, agriculture and transport workers). Almost half of the injured persons were doing a temporary job task at the time of the injury. Industry was coded in accordance with the company's main func-
Table 1. Distribution of sex, age, injury severity, job task and industry risk level among emergency department users treated for an occupational injury during 2013.

\begin{tabular}{lcc}
\hline Characteristics & \multicolumn{2}{c}{ Participants } \\
\cline { 2 - 3 } & $\mathrm{N}$ & $\%$ \\
\hline All injured persons & 1693 & 100 \\
Sex & & \\
$\quad$ Female & 376 & 22 \\
$\quad$ Male & 1317 & 78 \\
Age (years) & & \\
$\quad<30$ & 458 & 27 \\
$\geq 30$ & 1235 & 73 \\
Injury severity & & \\
$\quad$ Minor & 1130 & 67 \\
Major & 563 & 33 \\
Job task a & & \\
$\quad$ Temporary & 753 & 45 \\
$\quad$ Stationary & 936 & 55 \\
Job risk level b & & \\
High & & 32 \\
Intermediate & 543 & 29 \\
Low & 485 & 39 \\
\hline
\end{tabular}

${ }^{a}$ At individual level (missing $\mathrm{N}=4$ ).

${ }^{\mathrm{b}}$ At industry level.

tion and was transformed into 12 industrial sectors using the Danish industrial classification system (30). These sectors were subsequently classified into three job risk levels: "low" (ie, trade and services, social services, education, health care, and public administration, hotel and restorations), "intermediate" (ie, metal industries, other manufacturing industries and food industries), and "high" (ie, construction, transport, and agriculture) risk sectors (30). For further details on data collection and information on respondents versus non-respondents, please see Oesterlund et al $(26,31)$.

\section{Statistical analysis}

In the matched-pair interval approach, OR are calculated like a matched case-control study; only the discordant pairs (varying in relation to exposure) are of interest (16, 32). Informative pairs include those who were exposed on the previous workday, but not just before the injury or vice versa. Uninformative pairs have the same exposure status at both times. This means that injured persons who were exposed in the case period but unexposed in the control period are divided by injured persons who were exposed in the control period but unexposed in the case period. The control period was the previous work day at the same time when the injury occurred. Previous studies have experienced overlapping hazard and case-periods for case periods closer to the injury $(21,23)$. For persons with irregular work schedules, the control period was selected taking into account the number of hours worked before the injury. OR and corresponding $95 \%$ confidence intervals $(95 \% \mathrm{CI})$ for an occupational injury for each transient risk factor and relevant covariates (age, sex, 
injury severity, industry risk level, and job task) were estimated using conditional logistic regression (16).

The study size did not allow for detailed multi-stratified analyses due to insufficient number of informative pairs. However, patterns of simultaneous exposures were analyzed with Venn diagrams (available on request) and were controlled for most influential exposures in the matched-pair interval approach.

\section{Results}

Of the 1693 participants, $76 \%(\mathrm{~N}=1285)$ reported that they had been exposed to $\geq 1$ transient risk factors at the time of the injury, $38 \%$ were exposed to 1 risk factor, $25 \%$ were exposed to 2 risk factors, and only $13 \%$ were exposed to $>2$ risk factors. To address this, supplementary analyses using Venn diagrams were performed, which showed very little overlap by exposures. The most commonly overlapping transient risk factors were "malfunctioning machinery and material" and "altered surroundings". Controlling for these two transient risk factors independently showed the same pattern as seen in table 2 (max OR change 1) and tables 3-5 (max OR change 3 , in few cells). Further estimation of confounding or modification was not possible due to small sample sizes.

Table 2 shows the number of exposures to each risk factor and the matched OR compared to periods without these exposures. The largest injury risks were associated with broken machines or materials (OR 20.6, 95\% CI 13.5-33.3), altered surroundings (OR 20.9, 95\% CI 12.3-38.8) and non-routine task (OR 8.2, 95\% CI 5.3-13.1). Exposure to time pressure (OR 1.6, 95\% CI 1.3-2.1), feeling sick (OR 2.7, 95\% CI 1.9-3.9) and being distracted by someone (OR 3.1, 95\% CI 2.3-4.2) were associated with a smaller increased risk of occupational injury. Risk of occupational injury was generally significantly related to work-practice-related or equipment factors and 3 of 4 worker-related factors among workers in both age groups and for both sexes, with the matched risk estimates being similar, except for practice-related factors where a 2-3 times increased risk was seen for injured persons $>30$ years (table 3 ). Similar tendencies were seen for job task and industry risk level subgroups, but the risk of an occupational injury associated with a non-routine task in a stationary job (OR 11.7, 95\% CI 6.1-25.0) was double that for a non-routine task in a temporary job (OR 6.0, 95\% CI 3.3-11.7), see table 4. Working with broken machinery or materials seemed to be associated with increased risk of injury with increasing industry risk level ie, ranging from low risk industries (OR 15.0, 95\% CI 7.0-32.2) to high risk industries (OR 26.4, 95\% CI 12.4-56.2) (table 4). As shown in table 5, higher injury severity
Table 2. Risk of occupational injury in relation to exposure to transient risk factors, using the matched-pair interval approach, among emergency department users treated for an occupational injury during 2013. [OR=odds ratio (conditional logistic regression); $95 \% \mathrm{Cl}=95 \%$ confidence intervals]

\begin{tabular}{|c|c|c|c|c|c|c|}
\hline $\begin{array}{l}\text { Transient risk } \\
\text { factor }\end{array}$ & Total a & Exposed ${ }^{b}$ & $\begin{array}{l}\text { Proportion } \\
\text { exposed }\end{array}$ & IP c & OR & $95 \% \mathrm{Cl}$ \\
\hline \multicolumn{7}{|l|}{ Worker-related } \\
\hline Time pressure & 1652 & 337 & 0.20 & 298 & 1.6 & $1.3-2.0$ \\
\hline $\begin{array}{l}\text { Disagreement } \\
\text { with someone }\end{array}$ & 1661 & 57 & 0.03 & 57 & 1.4 & $0.8-2.3$ \\
\hline Feeling sick & 1643 & 272 & 0.16 & 151 & 2.7 & $1.9-3.8$ \\
\hline $\begin{array}{l}\text { Distracted by } \\
\text { someone }\end{array}$ & 1652 & 256 & 0.15 & 245 & 3.1 & $2.3-4.1$ \\
\hline \multicolumn{7}{|l|}{ Practice-related } \\
\hline $\begin{array}{l}\text { Non-routine } \\
\text { task }\end{array}$ & 1663 & 302 & 0.18 & 220 & 8.2 & $5.3-12.5$ \\
\hline $\begin{array}{l}\text { Altered } \\
\text { surroundings }\end{array}$ & 1656 & 422 & 0.25 & 307 & 20.9 & $12.2-35.8$ \\
\hline \multicolumn{7}{|l|}{ Equipment-related } \\
\hline $\begin{array}{l}\text { Broken machine } \\
\text { or materials }\end{array}$ & 1655 & 555 & 0.33 & 476 & 20.6 & $13.5-31.7$ \\
\hline \multicolumn{7}{|c|}{$\begin{array}{l}\text { Those with information at time of injury and the previous day for each } \\
\text { factor, ie, those who could contribute to informative pairs. } \\
\text { b Exposed at time of injury. } \\
\text { c Informative pairs include those who were exposed on previous work- } \\
\text { day, but not just before the injury or vice versa. Uninformative pairs } \\
\text { have the same exposure status at both times. Number of persons is } \\
\text { twice the number of informative pairs. }\end{array}$} \\
\hline
\end{tabular}

was associated with non-routine task (minor injury OR $7.1,95 \%$ CI $4.3-11.6$; severe injury OR $11.3,95 \%$ CI 4.9-26.1), and altered surroundings (minor injury OR $18.9,95 \%$ CI 9.7-36.9; severe injury OR 24.6, $95 \%$ CI 10.1-60.2) (table 5).

\section{Discussion}

This case-crossover study is unique as it is the first European case-crossover study on occupational injuries. Also, its large sample size and focus on injury risks across categories of industrial sectors, job task, and injury severity makes it unique. Based on the matched-pair interval approach, this case-crossover study highlights that a vast majority of all interviewed persons experienced a transient risk factor at the time of the injury.

The increased risk of occupational injury was especially associated with equipment- and work-practicerelated risk factors, with generally similar findings in subgroup analyses according to age, sex, and type of industrial sector. Remarkably lower, but still significant, risks were found for worker-related factors. Higher injury severity was also associated with work-practicerelated risk factors. The influence of specific injuries or industries was small when looking at stratum OR compared to overall OR, which means that some details might have been lost. 
Table 3. Matched-pair interval approach: risk of occupational injury after exposure to transient risk factors according to age and sex of emergency department users treated for an occupational injury during 2013. [OR=0dds ratio (conditional logistic regression); $95 \% \mathrm{Cl}=$ $95 \%$ confidence intervals].

\begin{tabular}{|c|c|c|c|c|c|c|c|c|c|c|c|c|}
\hline \multirow[t]{2}{*}{ Transient risk factor } & \multicolumn{3}{|c|}{ Aged $<30$ years } & \multicolumn{3}{|c|}{ Aged $\geq 30$ years } & \multicolumn{3}{|c|}{ Female } & \multicolumn{3}{|c|}{ Male } \\
\hline & $I P^{a}$ & $\mathrm{OR}$ & $95 \% \mathrm{Cl}$ & $\mathrm{IPa}$ & $\mathrm{OR}$ & $95 \% \mathrm{Cl}$ & $\mathrm{IPa}$ & $\mathrm{OR}$ & $95 \% \mathrm{Cl}$ & $\mathrm{IP}^{\mathrm{a}}$ & $\mathrm{OR}$ & $95 \% \mathrm{Cl}$ \\
\hline \multicolumn{13}{|l|}{ Worker-related } \\
\hline Time pressure & 105 & 1.1 & $0.8-1.6$ & 193 & 2.0 & $1.5-2.7$ & 85 & 1.5 & $1.0-2.3$ & 213 & 1.7 & $1.3-2.2$ \\
\hline Disagreement with someone & 21 & 1.3 & $0.6-3.2$ & 36 & 1.4 & $0.7-2.7$ & 20 & 1.9 & $0.7-4.7$ & 37 & 1.2 & $0.6-2.2$ \\
\hline Feeling sick & 73 & 2.5 & $1.5-4.1$ & 78 & 2.9 & $1.7-4.8$ & 32 & 1.7 & $0.8-3.4$ & 119 & 3.1 & $2.0-4.7$ \\
\hline Distracted by someone & 73 & 2.0 & $1.3-3.3$ & 172 & 3.8 & $2.6-5.5$ & 75 & 5.2 & $2.8-9.7$ & 170 & 2.5 & $1.8-3.5$ \\
\hline \multicolumn{13}{|l|}{ Practice-related } \\
\hline Non-routine task & 62 & 5.2 & $2.6-10.2$ & 158 & 10.3 & $5.9-17.8$ & 53 & 4.3 & $2.2-8.6$ & 167 & 10.9 & $6.3-18.9$ \\
\hline Altered surroundings & 72 & 9.3 & $4.3-20.2$ & 235 & 32.6 & $15.4-69.1$ & 75 & 36.5 & $9.0-148.7$ & 232 & 18.3 & $10.3-32.8$ \\
\hline \multicolumn{13}{|l|}{ Equipment-related } \\
\hline Broken machine or materials & 135 & 18.3 & 8.5 & 341 & 21.7 & 13.0 & 79 & 14.8 & $6.0-36.6$ & 397 & 22.4 & 13.8 \\
\hline
\end{tabular}

a Informative pairs include injured persons who were exposed previous workday, but not before the injury and vice versa.

Table 4. Matched-pair interval approach: risk of occupational injury after exposure to a transient risk factor according to job task and industrial risk level among emergency department users treated for an occupational injury during 2013. [OR=0dds ratio (conditional logistic regression), $95 \% \mathrm{Cl}=95 \%$ confidence intervals]

\begin{tabular}{|c|c|c|c|c|c|c|c|c|c|c|c|c|c|c|c|}
\hline \multirow[t]{3}{*}{ Transient risk factor } & \multicolumn{6}{|c|}{ Job task (individual level) } & \multicolumn{9}{|c|}{ Job risk level (industry level) } \\
\hline & \multicolumn{3}{|c|}{ Temporary } & \multicolumn{3}{|c|}{ Stationary } & \multicolumn{3}{|c|}{ Low } & \multicolumn{3}{|c|}{ Intermediate } & \multicolumn{3}{|c|}{ High } \\
\hline & IP a & $\mathrm{OR}$ & $95 \% \mathrm{Cl}$ & IP a & $\mathrm{OR}$ & $95 \% \mathrm{Cl}$ & $\mathrm{IP}$ a & $\mathrm{OR}$ & $95 \% \mathrm{Cl}$ & $\mathrm{IP}$ a & $\mathrm{OR}$ & $95 \% \mathrm{Cl}$ & $\mathrm{IP}$ a & OR & $95 \% \mathrm{Cl}$ \\
\hline \multicolumn{16}{|l|}{ Worker-related } \\
\hline Time pressure & 99 & 1.8 & $1.2-2.8$ & 197 & 1.5 & $1.1-2.0$ & 117 & 1.6 & $1.1-2.3$ & 84 & 1.5 & $1.0-2.4$ & 97 & 1.7 & $1.1-2.6$ \\
\hline Disagreement with someone & 19 & 0.7 & $0.3-1.8$ & 38 & 1.9 & $1.0-3.8$ & 32 & 2.6 & $1.2-5.5$ & 9 & 1.2 & $0.3-4.7$ & 16 & 0.5 & $0.2-1.3$ \\
\hline Feeling sick & 64 & 2.8 & $1.6-4.8$ & 85 & 2.7 & $1.7-4.3$ & 49 & 2.5 & $1.3-4.6$ & 36 & 2.3 & $1.1-4.6$ & 66 & 3.1 & $1.8-5.5$ \\
\hline Distracted by someone & 88 & 3.4 & $2.1-5.6$ & 156 & 2.9 & $2.0-4.2$ & 113 & 2.8 & $1.8-4.2$ & 64 & 2.8 & $1.6-4.8$ & 68 & 4.2 & $2.3-7.7$ \\
\hline \multicolumn{16}{|l|}{ Practice-related } \\
\hline Non-routine task & 91 & 6.0 & $3.3-10.8$ & 127 & 11.7 & $6.1-22.3$ & 85 & 7.5 & $3.9-14.5$ & 62 & 14.5 & $5.3-39.9$ & 73 & 6.3 & $3.2-12.3$ \\
\hline Altered surroundings & 147 & 23.5 & $10.4-53.2$ & 159 & 18.9 & $9.3-38.4$ & 124 & 23.8 & $9.7-58.2$ & 59 & 13.7 & $5.0-37.9$ & 124 & 23.8 & $9.7-58.2$ \\
\hline \multicolumn{16}{|l|}{ Equipment-related } \\
\hline Broken machine or materials & 224 & 7.7 & $9.9-31.6$ & 249 & 23.9 & $12.7-45.0$ & 112 & 15.0 & $7.0-32.2$ & 172 & 20.5 & $10.1-41.7$ & 192 & 26.4 & $12.4-56.2$ \\
\hline
\end{tabular}

a Informative pairs include injured persons who were exposed previous workday, but not before the injury and vice versa.

\section{Strengths and weaknesses}

An important strength of the case-crossover design is that interpersonal bias is avoided due to self-matching.

This implies that factors like age, experience, and gender that are known to affect the risk of an injury are not confounding the results $(33,34)$. However, there are especially two limitations in regards to the case-crossover study: exposure suspicious and recall bias $(35,36)$.

Exposure suspicious bias refers to the fact that if the injury has occurred before data gathering, the injured person's own ideas, beliefs and interpretations of the causes of the injury may affect reporting of exposure, which may lead to over estimation of the risk. One previous case-crossover study has targeted this problem. Researchers kept a log on the level of exposure for the study population and subsequently assessed the level of agreement between self-reports and direct observations. Excellent agreement was found for work location, task, tools, and tools sharpening. Very poor agreement was found for being distracted, rushing, slipping, or falling (37). All in all it seems that some of our measured tran- sient exposures might be biased to a certain extent and some risk estimates might be too high $(32,36)$. This is why the direction of risk estimates, and especially, the size of and relative distribution between risk estimates are of more interest than the specific level of OR themselves.

Recall bias refers to the elapsed time between injury and interview, which may have given rise to memory bias, especially concerning exposure events on the control day. If recall diminishes over days or weeks, then an overestimation of some transient risk factors, as mentioned before, at the time of the injury coupled with underestimation in the control periods would result in artificially high risk estimates. Some studies reinterview subjects and indicate that this is not a problem for most transient risk factors $(14,35)$.

Determination of a correct hazard period is a methodological challenge in any case-crossover study, especially for worker-related factors. As in several other work injury case-cross-over studies, the same hazard period for all transient risk factors was chosen for our study $(18,2-8,39)$. However, the hazard period is likely to vary between different transient risk factors, eg, 
Table 5. Matched-pair interval approach: risk of occupational injury after exposure to a transient risk factor according to injury severity among emergency department users treated for an occupational injury during 2013. [OR=0dds ratio; $95 \% \mathrm{Cl}=95 \%$ confidence intervals]

\begin{tabular}{|c|c|c|c|c|c|c|}
\hline \multirow{2}{*}{$\begin{array}{l}\text { Transient risk } \\
\text { factor }\end{array}$} & \multicolumn{3}{|c|}{ Minor injury } & \multicolumn{3}{|c|}{ Severe injury } \\
\hline & IP a & OR & $95 \% \mathrm{Cl}$ & $I P$ a & OR & $95 \% \mathrm{Cl}$ \\
\hline \multicolumn{7}{|l|}{ Worker-related } \\
\hline Time pressure & 192 & 1.5 & $1.1-2.0$ & 106 & 1.9 & $1.3-2$ \\
\hline $\begin{array}{l}\text { Disagreement with } \\
\text { someone }\end{array}$ & 42 & 1.3 & .5 & 15 & 1.5 & $05-$ \\
\hline Feelin & 110 & 2.7 & & 41 & 7 & \\
\hline Distra & 166 & 3.0 & 2.1 & 79 & 3.2 & 1.9 \\
\hline \multicolumn{7}{|l|}{ Practice-related } \\
\hline Non-routine task & 146 & 7.1 & & 74 & 11.3 & $4.9-26.1$ \\
\hline Altered surroundings & 179 & 18.9 & $9.7-36.9$ & 128 & 24.6 & $10.1-60$ \\
\hline \multicolumn{7}{|l|}{ Equipment-related } \\
\hline $\begin{array}{l}\text { Broken machine or } \\
\text { materials }\end{array}$ & 330 & 24.4 & $14.0-42.5$ & 146 & 15.2 & 7.8 \\
\hline
\end{tabular}

a Informative pairs include injured persons who were exposed previous workday, but not before the injury and vice versa.

the hazard period of broken machinery or materials is presumably different to that of time pressure or feeling sick. The exact length of the induction time and hazard period for a risk factor cannot be precisely measured in our study due to the framing of the questionnaire. The injured persons were asked for exposure "just before the injury" in the case period, which was compared to a control period "the previous day at the same time of the injury". For some of the worker-related risk factors, the hazard period could exceed the case period, for instance concerning feeling sick or for time pressure. When the hazard period exceeds the control period there will be an underestimation of the risk. This could be the explanation of the low OR for many of the worker-related risk factors. Previous studies have also pointed out difficulties in determining correct hazard periods $(14,15,27)$. The issue of the length of hazard period for different transient risk factors should be thoroughly analyzed in future studies.

Another possible weakness of this study is the lack of adjustment for multiple simultaneous exposures. However, the Venn diagram analysis showed that the overlapping subgroups were too small in size, and adjusting for a few single factors did not change the risk estimates substantially.

\section{Equipment-related factors}

Consistent with findings from other case-crossover studies, the use of malfunctioning machinery or material was associated with a highly elevated risk of an occupational injury $(14,21)$. This supports findings from other study designs highlighting the importance of, eg, machine safety $(5,13)$. Furthermore, our results indicate that working with broken machinery and materials is more hazardous in high-risk industries than in intermediateand low-risk ones. An explanation for these findings could be differences in work tasks and equipment used in high- and low-risk jobs. For example, large, nonstationary, and hand-held machines are predominantly used in farming and construction and are probably more dangerous than the predominantly stationary and encapsulated machines used in most of the manufacturing industry today. In Denmark, the defined high-risk industries are also dominated by male, often young workers, who in general are more risk-oriented than female workers $(2,3,40)$. These results highlight the importance of machine maintenance as well as sufficient operator training in handling broken or malfunctioning machines and materials, ie, preparing for when things go wrong, so that workers know how to react when a procedure does not go as expected. This may also point to more climate- and/or culture-based approaches to safety, which should be prioritized by leaders as well as workers in all situations, including the avoidance of unintentional work pressure that can lead to unsafe handling of machinery $(41,42)$.

\section{Work-practice-related factors}

Again consistent with previous case-crossover studies, unusual work methods or unfamiliar tasks were associated with high injury risk $(27,28)$. Only a few other studies have addressed the importance of practicerelated factors as a risk factor for occupational injuries, highlighting the importance of further research in this field (29). For non-routine tasks, it is remarkable that the risk of injury was almost twice as high for workers in stationary versus temporary jobs. This could indicate that workers in temporary or more dynamic jobs are routinely better prepared to adjust to varying job functions than workers in stationary jobs, and thus minimize their risk of occupational injury. Moreover, practice-related factors showed higher risk estimates for severe versus minor injuries. One reason could be changes in working surroundings, eg, wet floors and messiness on worksites that can lead to trips and falls and result in serious injuries $(43,44)$. The high OR regarding practice-related factors also indicate potential preventive benefits of an improved safety climate or culture, where long-term priorities such as maintenance and cleanliness are a key focus, independent of work task and surroundings. Surprisingly, our study showed that risk estimates were higher among older persons (age group $\geq 30$ years) for practice-related factors, whereas many previous studies have shown that young people in general have considerably higher risks of occupational injury than older people (45). The non-response analyses for our study revealed that young persons (aged $<30$ years) were underrepresented in the analysis sample. Transient risk 
factors sensitive to age are thus important and should be interpreted carefully, especially for worker-related factors (46).

\section{Worker-related factors}

In accordance with other case-crossover studies, transient worker-related exposures were associated with lower injury risk than practice- and equipment-related factors as also shown regardless of the analytic approach (47). Time pressure, being distracted and feeling unwell were the most common factors that increased the risk of an occupational injury. Results revealed that $20 \%$ of all injured persons experienced time pressure at the time of their injury. While this is a relatively high number, the OR was relatively low, possibly because many of the injured persons were also exposed to time pressure in the control period, which was typically the same time on the previous day. This indicates that many injured persons experience time pressure for a prolonged period and not just on the day of injury or just before the injury. The same applies to "being distracted" and "feeling sick", where the number of exposed is also relatively high in both the case and the control period for the matchedpair interval approach. These examples could indicate that some worker-related factors are a part of everyday work life and are not transient, as assumed here. Other studies have reported the same experience for some worker-related factors, for instance feeling rushed, fatigued, or use of alcohol (27). Other methods may thus be more specific for analysis of worker-related factors, including confirmation that factors are actually transient. "Disagreement with someone" did not have a significant effect in the matched-pair interval approach, presumably related to the small time difference between cases and controls. Results from previous case-crossover studies have shown narrower CI and more precise calculation of risk estimates when using the usual frequency approach $(14,21)$, which indicates that further evaluation of this approach is warranted.

\section{Concluding remarks}

The risk of occupational injury was significantly associated with transient exposure to equipment- and workpractice-related factors. The overall risk of injury did not vary substantially in relation to worker-related factors within subgroups of sex, injury severity, type of job task, and industry risk level. Equipment-related exposures were associated with higher injury risk with increasing industrial risk level, while severe injuries were more associated with work-practice-related factors. Transient risk factors sensitive to age are important and should be interpreted carefully in particular for practicerelated factors. Our results point to a need for improving workplace factors regarding work practice (eg, preparing workers for non-routine tasks and altered surroundings) and equipment (eg, minimizing broken machinery and materials) and, to a lesser degree, worker-related factors.

\section{Acknowledgements}

The authors would like to thank the workers who participated in the study as well as the OUH and $\mathrm{HH}$ administrative personnel for their assistance in the study. Claire Gudex, Department of Clinical Research, University of Southern Denmark assisted in language editing of the final manuscript.

\section{Funding}

The Danish Working Environment Authority supported this study [grant number 20110081325/3].

\section{Ethics review and approval}

The Danish Data Protection Agency approved this project (case number: 14/21105).

\section{Competing interest}

The authors declare no conflict of interest.

\section{References}

1. Nenonen N, Saarela KL, Takala J, Kheng LG, Yong E, Ling LS et al. Global estimates of occupational accidents and fatal work-related diseases in 2014. Finland: International Labour Office, ILO.; 2014.

2. Lander F, Nielsen KJ, Rasmussen K, Lauritsen JM. Patterns of work injuries: cases admitted to emergency room treatment compared to cases reported to the Danish Working Environment Authority during 2003-2010. J Occup Environ Med. 2014;71(2):97-103. https://doi.org/10.1136/ oemed-2013-101559.

3. Lander F, Nielsen KJ, Rasmussen K, Lauritsen JM Underrapportering af arbejdsulykker . LO-rapport, Version 2.0: En ny vinkel på underrapportering. [Underreporting of work injuries, A new perspective of underreporting]. Danish Confederation of Trade Unions. 2015. (in Danish, summary in English).

4. Overvågning af arbejdsmiljø og arbejdsmiljøindsats Overvågningsrapport 2008 [Surveillance of the work environment and efforts of improvement - Annual report 2008]. Danish Working Environment Authority, 2010. Report ISBN nr. 87-7534-599-4. (In Danish). 
5. Mittleman MA, Maldonado G, Gerberich SG, Smith GS, Sorock GS. Alternative approaches to analytical designs in occupational injury epidemiology. Am J Ind Med. 1997;32(2):129-41. https://doi.org/10.1002/(SICI)10970274(199708)32:2<129::AID-AJIM4>3.0.CO;2-U.

6. Sorock GS, Lombardi DA, Courtney TK, Cotnam JP, Mittleman MA. Epidemiology of occupational acute traumatic hand injuries: a literature review. Saf Sci. 2001;38(3):241-56. https://doi.org/10.1016/S0925-7535(01)00004-2.

7. Ruff T, Coleman P, Martini L. Machine-related injuries in the US mining industry and priorities for safety research. Int J Inj Contr Saf Promot. 2011;18(1):11-20. https://doi.org/10.1080 $/ 17457300.2010 .487154$.

8. Villanueva V, Garcia AM. Individual and occupational factors related to fatal occupational injuries: a case-control study. Accid Anal Prev. 2011;43(1):123-7. https://doi.org/10.1016/j. aap.2010.08.001.

9. Gerberich SG, Gibson RW, French LR, Lee TY, Carr WP, Kochevar L et al. Machinery-related injuries: regional rural injury study--I (RRIS--I). Accid Anal Prev. 1998;30(6):793804. https://doi.org/10.1016/S0001-4575(98)00032-3.

10. Ghosh AK, Bhattacherjee A, Chau N. Relationships of working conditions and individual characteristics to occupational injuries: a case-control study in coal miners. J Occup Health. 2004;46(6):470-80. https://doi.org/10.1539/joh.46.470.

11. Swanton AR, Young TL, Leinenkugel K, Torner JC, PeekAsa C. Nonfatal tractor-related injuries presenting to a state trauma system. J Safety Res. 2015;53:97-102. https://doi. org/10.1016/j.jsr.2015.03.002.

12. Jensen OC. Non-fatal occupational fall and slip injuries among commercial fishermen analyzed by use of the NOMESCO injury registration system. Am J Ind Med. 2000;37(6):637-44. https://doi.org/10.1002/(SICI)10970274(200006)37:6<637::AID-AJIM8>3.0.CO;2-3.

13. Sprince NL, Park H, Zwerling C, Lynch CF, Whitten PA, Thu $\mathrm{K}$ et al. Risk factors for machinery-related injury among Iowa farmers: a case-control study nested in the Agricultural Health Study.Int J Occup Environ Health . 2002;8(4):332-8. https:// doi.org/10.1179/10773520280033864.

14. Sorock GS, Lombardi DA, Hauser R, Eisen EA, Herrick RF, Mittleman MA. A case-crossover study of transient risk factors for occupational acute hand injury. J Occup Environ Med. 2004;61(4):305-11. https://doi.org/10.1136/ oem.2002.004028.

15. Checkoway H, Pearce N, Kriebel D. Selecting appropriate study designs to address specific research questions in occupational epidemiology. J Occup Environ Med. 2007;64(9):633-8. https://doi.org/10.1136/oem.2006.029967.

16. Maclure M, Mittleman MA. Should we use a case-crossover design? Annu Rev Public Health. 2000;21:193-221. https:// doi.org/10.1146/annurev.publhealth.21.1.193.

17. Checkoway H, Pearce N, Kriebel D. Selecting appropriate study designs to address specific research questions in occupational epidemiology. J Occup Environ Med. 2007;64(9):633-8. https://doi.org/10.1136/oem.2006.029967.
18. Lander L, Sorock G, Stentz TL, Smith LM, Mittleman M, Perry MJ. A case-crossover study of laceration injuries in pork processing. J Occup Environ Med. 2012;69(6):410-6. https:// doi.org/10.1136/oemed-2011-100339.

19. Blackburn J, Levitan EB, MacLennan PA, Owsley C, McGwin G, Jr. A case-crossover study of risk factors for occupational eye injuries. J Occup Environ Med. 2012;54(1):42-7. https:// doi.org/10.1097/JOM.0b013e3182398e1a.

20. Jin K, Lombardi DA, Courtney TK, Sorock GS, Li M, Pan R et al. A case-crossover study of work-related acute traumatic hand injuries in the People's Republic of China. Scand J Work Environ Health. 2012;38(2):163-70. https://doi.org/10.5271/ sjweh.3262.

21. Choi WJ, Cho SI, Han SH. A case-crossover study of transient risk factors for occupational traumatic hand injuries in Incheon, Korea. J Occup Health. 2012;54(1):64-73. https:// doi.org/10.1539/joh.11-0101-FS.

22. Fisman DN, Harris AD, Sorock GS, Mittleman MA. Sharpsrelated injuries in health care workers: a case-crossover study. Am J Med. 2003;114(8):688-94. https://doi.org/10.1016/ S0002-9343(03)00082-2.

23. Sorock GS, Lombardi DA, Gabel CL, Smith GS, Mittleman MA. Case-crossover studies of occupational trauma: methodological caveats. Inj Prev. 2001;7-38-42. https://doi. org/10.1136/ip.7.suppl_1.i38

24. Hvad er en arbejdsulykke [Definition of an occupational injury]. http://arbejdstilsynet.dk/da/selvbetjening/anmeldarbejdsulykker/hvad-er-en-arbejdsulykke (In Danish, accessed 22nd February 2016).

25. Pedersen CB. The Danish Civil Registration System. Scand J Public Health. 2011;39(7). https://doi. org/10.1177/1403494810387965.

26. Oesterlund AH, Lander F, Rytter S, Lauritsen J. Selection bias in follow-up interviews with individuals attending the emergency department for occupational injuries. Inj Prev. 2016. [Epub ahead of print] https://doi.org/10.1136/ injuryprev-2016-042034.

27. Chen SY, Fong PC, Lin SF, Chang CH, Chan CC. A casecrossover study on transient risk factors of work-related eye injuries. J Occup Environ Med. 2009;66(8):517-22. https:// doi.org/10.1136/oem.2008.042325.

28. Chow CY, Lee H, Lau J, Yu IT. Transient risk factors for acute traumatic hand injuries: a case-crossover study in Hong Kong. J Occup Environ Med. 2007;64(1):47-52. https://doi. org/10.1136/oem.2006.028589.

29. McGwin G, Jr., Taylor AJ, MacLennan PA, Rue LW, 3rd. Unusual job activities as a risk factor for occupational injuries. Occup Med(Lond). 2005;55(1):66-8. https://doi.org/10.1093/ occmed/kqi020.

30. Dansk Branchekode 2007 DB07 [Danish Industrial Classification of All Economic Activities 2007] . Statistics Denmark, 2007. ISBN 978-87-501-2055-1 . (In Danish)

31. Oesterlund AH, Lander F, Lauritsen J. A case-crossover study of transient risk factors influence on occupational injuries: a study protocol based on a review of previous studies. Inj Prev 2016;22:375. https://doi.org/10.1136/ 
injuryprev-2014-041371.

32. Rothman KJ. Modern Epidemiology. Boston, MA: Little, Brown and Co.;1986.

33. Kunar BM, Bhattacherjee A, Chau N. Relationships of job hazards, lack of knowledge, alcohol use, health status and risk taking behavior to work injury of coal miners: a case-control study in India. J Occup Health. 2008;50(3):236-44. https:// doi.org/10.1539/joh.L7054.

34. Chau N, Bhattacherjee A, Kunar BM. Relationship between job, lifestyle, age and occupational injuries. Occup Med (Lond). 2009;59(2):114-9. https://doi.org/10.1093/occmed/ kqp002.

35. Moller J, Hessen-Soderman AC, Hallqvist J. Differential misclassification of exposure in case-crossover studies. Epidemiology. 2004;15(5):589-96. https://doi. org/10.1097/01.ede.0000135177.10332.42.

36. Sackett D. Bias in analytic research. J Chronic Dis. 1979;32(12):51-63. https://doi.org/10.1016/0021-9681(79)90012-2.

37. Lander L, Sorock G, Stentz TL, et al. Validation of selfreported occupational exposures in meatpacking workers. Am J Ind Med. 2009;52(9):707-15. https://doi.org/10.1002/ ajim.20721.

38. Lombardi DA, Sorock GS, Hauser R, Nasca PC, Eisen EA, Herrick RF et al. Temporal factors and the prevalence of transient exposures at the time of an occupational traumatic hand injury. J Occup Environ Med. 2003;45(8):832-40. https://doi.org/10.1097/01.jom.0000083030.56116.1a.

39. Sorock GS, LombardiDA, Peng DK, Hauser R, Eisen EA, Herrick RF et al. Glove use and the relative risk of acute hand injury: a case-crossover study. J Occup Environ Hyg. 2004;1(3):182-90. https://doi.org/10.1080/15459620490424500.
40. British Safety Council, Ensuring the safety and health of young workers, British Safety Council, London, 2010. Available from: https:/www.britsafe.org/sites/default/files//editor/ Young_Workers_Report.pdf

41. Nielsen KJ. Improving safety culture through the health and safety organization: a case study. J Safety Res. 2014;48:7-17. https://doi.org/10.1016/j.jsr.2013.10.003.

42. Guldenmund FW. The nature of safety culture: a review of theory and research. Saf Sci. 2000;34(1-3):215-57. https:// doi.org/10.1016/S0925-7535(00)00014-X

43. Rautiainen RH, Ledolter J, Donham KJ, Ohsfeldt RL, Zwerling C. Risk factors for serious injury in Finnish agriculture. Am J Ind Med. 2009;52(5):419-28. https://doi.org/10.1002/ ajim.20688.

44. Saari J, Tech D, Lahtela J. Work conditions and accidents in three industries. Scand J Work Environ Health. 1981;7 Suppl 4:97-105.

45. Lander F, Nielsen KJ, Lauritsen J. Work injury trends during the last three decades in the construction industry. Saf Sci. 2016;85:60-6. https://doi.org/10.1016/j.ssci.2015.10.013.

46. Chau N, Wild P, Dehaene D, Benamghar L, Mur JM, Touron C. Roles of age, length of service and job in work-related injury: a prospective study of 446120 person-years in railway workers. J Occup Environ Med. 2010;67(3):147-53. https:// doi.org/10.1136/oem.2008.043281.

47. Lombardi DA, Sorock GS, Lesch MF, Hauser R, Eisen EA, Herrick RF et al. A reliability study of potential risk factors for acute traumatic occupational hand injuries. Am J Ind Med. 2002;42(4):336-43. https://doi.org/10.1002/ajim.10120.

Received for publication: 8 August 2016 